\title{
Correction to: Genetic Analysis of Migration Pattern of Female Bonobos (Pan paniscus) Among Three Neighboring Groups
}

\author{
Shintaro Ishizuka ${ }^{1,2} \cdot$ Kazuya Toda $^{1} \cdot$ Takeshi Furuichi $^{1}$ \\ Published online: 19 June 2020 \\ (C) Springer Science+Business Media, LLC, part of Springer Nature 2020
}

\section{Correction to: International Journal of Primatology (2020) 41:401-414 https://doi.org/10.1007/s10764-019-00106-w}

The original version of this article unfortunately contained mistakes. The changes are shown below:

1. In the article, the estimated frequency of female migration into neighboring groups in bonobos is written as $4.5 / 7.48(60 \%)$. However, the correct estimate is 4.5 / $8.55(53 \%)$.

2. Table 5 shows that the estimated age (2017) of Co (PW group) is $44 \mathrm{y}$ and that of $\mathrm{Dk}$ (PW group) is $49 \mathrm{y}$. However, these data are reversed. The correct information is that the estimated age (2017) of Co is $49 \mathrm{y}$ and that of Dk is $44 \mathrm{y}$.

The authors apologize for these mistakes.

The online version of the original article can be found at https://doi.org/10.1007/s10764-019-00106-w

Shintaro Ishizuka

ishizuka.shintaro.37x@kyoto-u.jp

1 Primate Research Institute, Kyoto University, Aichi, Japan

2 Japan Society for Promotion of Science, Tokyo, Japan 